\title{
Contrasting phosphate acquisition of mycorrhizal fungi with that of root hairs using the root hairless barley mutant
}

\author{
IVER JAKOBSEN ${ }^{1}$, BAODONG CHEN $^{2}$, LISA MUNKVOLD ${ }^{1}$, THORBEN LUNDSGAARD $^{3}$ \& YONG-GUAN ZHU YH $^{2}$ \\ ${ }^{1}$ Biosystems Department, Ris $\varnothing$ National Laboratory, DK-4000 Roskilde, Denmark, ${ }^{2}$ Department of Soil Environmental \\ Science, Research Center for Eco-Environmental Sciences, Chinese Academy of Sciences, Beijing 100085, China and \\ ${ }^{3}$ Department of Plant Biology, The Royal Veterinary and Agricultural University, Frederiksberg, DK-1871 Denmark
}

\begin{abstract}
Comparisons between plant species or cultivars differing in root hair length have indicated a major impact of root hairs on the mycorrhizal dependency of plants with respect to phosphate (P) uptake. The current study aimed to investigate this relationship by comparing directly the mycorrhizal dependency of a spontaneous root hairless mutant, $b r b$, in Hordeum vulgare cv Pallas and its wild type. Both brb and wild type were grown at different soil $P$ levels in association with different mycorrhizal fungi. $P$ uptake of $b r b$ and wild type was similar at high $P$ levels, but $P$ uptake by nonmycorrhizal $b r b$ plants at low $P$ levels was substantially lower than that of the non-mycorrhizal wild-type plants. However, $P$ uptake of the mutant was much increased by mycorrhizas and with one fungus, the additional $P$ uptake was effectively translated into increased plant growth. Roots of the mutant contained typical colonization structures and a radioactive tracer confirmed $P$ transport by the extraradical mycelium. This is the first direct evaluation of the relative effectiveness of root hairs and mycorrhizas. Mycorrhizas effectively substituted root hairs in $P$ uptake, whereas the additional $P$ was most often used less effectively in promoting plant growth than $P$ provided by root hairs.
\end{abstract}

Key-words: Hordeum vulgare; arbuscular mycorrhiza; phosphorus; root hair.

\section{INTRODUCTION}

The activity of plant $\mathrm{P}$ transporters in root epidermal cells usually leads to the formation of a P-depletion zone around roots because the uptake is proceeding faster than the diffusion-limited replenishment of the depleted soil (Nye \& Tinker 1977). Phosphorus acquisition of soil-grown plants will consequently depend on the physical exploration of the growth substrate beyond the $\mathrm{P}$ depletion zone and on the release of $\mathrm{P}$ mineralizing and solubilizing enzymes and organic acids. Length and density of root hairs increase at low P growth conditions (Föhse \& Jungk 1983; Ma et al.

Correspondence: Iver Jakobsen

E-mail: iver.jakobsen@risoe.dk 2001a) and the importance of root hairs for $P$ acquisition was shown by sensitivity analysis (Silberbush \& Barber 1983) and by comparison of P uptake between plant species, cultivars or mutants varying in root hair characteristics (Föhse, Claassen \& Jungk 1991; Gahoonia, Care \& Nielsen 1997; Bates \& Lynch 2000a). Monogenic mutants expressing phenotypic variation in root hair characteristics are tools for the unequivocal confirmation of the importance of root hairs. In maize, only mutants with defects in root hair development have been isolated (Wen \& Schnable 1994) and root hairless mutants have been isolated in Arabidopsis (Schiefelbein \& Somerville 1990; Schneider et al. 1998; Bates \& Lynch 2000a). A modelling approach demonstrated a substantial morphological synergism in root hair length, density, initiation and geometry for $\mathrm{P}$ acquisition in Arabidopsis (Ma et al. 2001b). In crop plants, root hairless mutants have been obtained in barley (Gahoonia et al. 2001) and in rice (Suzuki, Taketa \& Ichii 2003) only. The root hairless mutant in barley $b r b$ was recently used to confirm that root hairs are of immense importance for $\mathrm{P}$ acquisition in low-P environments, whereas they may be dispensable under high-P conditions (Gahoonia \& Nielsen 2003). The absence of root hairs in rice had no impact on $\mathrm{P}$ acquisition from solution culture, which confirms that root hairs are important to $\mathrm{P}$ uptake from $\mathrm{P}$-adsorbing growth media only (Suzuki et al. 2003). Furthermore, the similar performances of wild type and a root hairless mutant (rth 3-1) in maize reported by Wen \& Schnable 1994) and by Paszkowski \& Boller (2002) were probably related to the use of non-limiting $\mathrm{P}$ supplies.

The symbiotic arbuscular mycorrhizal (AM) fungi constitute another important pathway for P uptake by most plant species (Smith, Smith \& Jakobsen 2003). This mycorrhizal pathway is represented by a root external mycelium, which extends into the soil and thereby access $P$ far beyond the root $\mathrm{P}$ depletion zone (Jakobsen, Abbott \& Robson 1992a, b). The relative importance of mycorrhizas to $P$ uptake and growth differs between plants and early studies suggested that certain 'plants are obligatory mycotrophic in P-deficient soils if their root hairs are poorly developed' (Baylis 1970). Comparison of growth responses of mycorrhizal and non-mycorrhizal leguminous species differing in root hair length supported the hypothesis and it was suggested that root hairs and external hyphae act as alterna- 
tive, similar ways of shortening the distance for the diffusion of P in soil (Schweiger, Robson \& Barrow 1995). Another study of rye cultivars with long and short root hairs confirmed this relationship, but it was concluded that long root hairs were more important than mycorrhizas for the uptake of P from soil (Baon, Smith \& Alston 1994). Root hairs and root external hyphae may differ markedly in $\mathrm{P}$ uptake capacity, even when present at similar lengths. Phosphate uptake by the well-dispersed hyphae in the soil is probably not limited by depletion zones due to their small diameter (Barber 1984) whereas P uptake by the poorly dispersed root hairs may rapidly become limited by interhair competition (Baldwin, Tinker \& Nye 1972). This is reflected by the stronger $\mathrm{P}$ depletion in the root hair zone then in soil containing AM fungal mycelium (Joner et al. 1995).

The root hairless mutant isolated in barley represents a novel tool for directly comparing root hairs and mycorrhizas as adaptations for maintenance of a high $\mathrm{P}$ acquisition efficiency under low P conditions. Barley develops abundant mycorrhizas in low P or moderately P-deficient soils (Jensen \& Jakobsen 1980; Jakobsen \& Nielsen 1983) and mycorrhizas increased the growth of barley in low P soils (Clarke \& Mosse 1981; Jakobsen 1983). Such growth increases were absent in soils with higher and more adequate P levels (Jensen 1984; Khaliq \& Sanders 2000). The root hairless mutant $b r b$ is genotypically similar to its wild type apart from a monogenic mutation in the root hair trait (Gahoonia et al. 2001) and in the present work we hypothesized that colonization by mycorrhizal fungi would improve $\mathrm{P}$ acquisition of the mutant. Such a result would be in parallel with a previous observation that mycorrhizas could compensate for the reduction in growth of a maize mutant lacking lateral roots (Paszkowski \& Boller 2002).

Three short-term ( 3 or 4 week) experiments were carried out to test the following hypotheses: (1) a functional mycorrhiza can be established with a root hairless barley mutant as host plant; (2) mycorrhiza can substitute for root hairs and counteract plant growth depressions caused by absence of root hairs and (3) the degree of compensation by mycorrhizal fungi for lack of root hairs varies markedly among fungi. All experiments involved the factorial combination of the two barley genotypes and mycorrhizal fungi grown in a soil-sand substrate.

\section{MATERIALS AND METHODS}

Three experiments were carried out in this study. The spontaneous root hairless mutant (brb) in barley (Hordeum vulgare L.) and its wild type (cv. Pallas P02) were grown in all experiments in an irradiated $(10 \mathrm{kGy}, 10 \mathrm{MeV}$ electron beam) $1: 1$ mixture of sand and a moderately P-deficient moraine loam. Basal nutrients were mixed into the soil in the following amounts ( $\mathrm{mg} \mathrm{kg}^{-1}$ dry soil): $\mathrm{K}_{2} \mathrm{SO}_{4}, 75.0$; $\mathrm{CaCl}_{2} \cdot 5 \mathrm{H}_{2} \mathrm{O}, 75.0 ; \mathrm{CuSO}_{4} \cdot 5 \mathrm{H}_{2} \mathrm{O}, 2.1 ; \mathrm{ZnSO}_{4} \cdot 7 \mathrm{H}_{2} \mathrm{O}, 5.4$; $\mathrm{MnSO}_{4} \cdot \mathrm{H}_{2} \mathrm{O}, 10.5 ; \mathrm{CoSO}_{4} \cdot 7 \mathrm{H}_{2} \mathrm{O}, 0.39 ; \mathrm{NaMoO}_{4} \cdot 2 \mathrm{H}_{2} \mathrm{O}, 0.18$; $\mathrm{MgSO}_{4} \cdot 7 \mathrm{H}_{2} \mathrm{O}, 45.0$. This final soil had a $\mathrm{pH}\left(\mathrm{H}_{2} \mathrm{O}\right)$ of 6.7 and a $0.5 \mathrm{M} \mathrm{NaHCO}_{3}$ extractable $\mathrm{P}$ content (Olsen et al. 1954) of $9 \mu \mathrm{g} \mathrm{P} \mathrm{g}^{-1}$. The root growth medium of experiments 1 and 3 received no further $P$ whereas experiment 2 had 15 levels of P supply (see below). Both plant genotypes were inoculated with arbuscular mycorrhizal fungi or received no inoculum. The inoculum used in the three experiments was dry soil, containing spores and colonized root fragments, from pot cultures of different AM fungi (see below where 'BEG' numbers refer to the International Bank for the Glomeromycota and ' $\mathrm{V}$ ' numbers refer to the collection of $\mathrm{M}$. Vestberg, Finland) grown on Trifolium subterraneum L. in the same soil as described above. The inoculum was in all cases thoroughly mixed into the soil. All experiments had one plant per pot, and plants were maintained in a growth room with a $16 / 8 \mathrm{~h}$ day/night cycle with $21 / 16^{\circ} \mathrm{C}$ temperatures, respectively. Osram daylight lamps provided $550 \mu \mathrm{mol} \mathrm{m}{ }^{-2} \mathrm{~s}^{-1}$ PAR (400-700 nm) measured at the top of the canopy. Plants were watered daily to $60 \%$ of waterholding capacity by weight.

\section{Experiment 1}

The purpose was to characterize the $b r b$ mutant in terms of mycorrhiza formation and the function of the mycorrhizas in terms of hyphal $\mathrm{P}$ transport from soil to plant. Plants were grown in compartmented pots made from PVC tubing (50 mm outer diameter, $300 \mathrm{~mm}$ length) as described by Smith, Jakobsen \& Smith (2000). The root compartment contained $725 \mathrm{~g}$ soil, which was separated from a side compartment by a $25-\mu$ m nylon mesh impairing root penetration. The side arm contained $80 \mathrm{~g}$ soil amended with $50 \mu \mathrm{g}$ $\mathrm{KH}_{2} \mathrm{PO}_{4}-\mathrm{P} \mathrm{g}^{-1}$ soil and $4 \mathrm{kBq}$ carrier-free ${ }^{32} \mathrm{P}$ as orthophosphate (Amersham Biosciences UK Ltd., Buckinghamshire, $\mathrm{UK})$; this resulted in a specific ${ }^{32} \mathrm{P}$ activity of $36.5 \mathrm{kBq}$ $\mathrm{mg}^{-1} \mathrm{P}$ in $0.5 \mathrm{M} \mathrm{NaHCO}_{3}$ extracts of the soil (Olsen et al. 1954). Each of two plant genotypes ( $b r b$ mutant and wild type) were inoculated with the AM fungus Glomus mosseae (Nicol. \& Gerd.) Gerdemann \& Trappe (BEG 161) or not. Sixty grams of inoculum was mixed with $90 \mathrm{~g}$ soil and the $150 \mathrm{~g}$ was placed in the centre of the root compartment, at the level of the side arm. Each of the four treatments had four replicates. Pots were watered to $60 \%$ of the waterholding capacity and left for 1 week before planting. A solution of $\mathrm{NH}_{4} \mathrm{NO}_{3}$ was added periodically to provide a total of $100 \mathrm{mg} \mathrm{N}$ pot $^{-1}$. Plants were harvested after $28 \mathrm{~d}$; roots were washed and samples were taken for measurement of colonized root length and for characterization of mycorrhiza in $60-\mu \mathrm{m}$ transects of $0.5-\mathrm{cm}$ root sections cut by a freeze microtome. Transects were stained with acid fuchsin and investigated by fluorescence microscopy. Dried ground root and shoot samples were digested in a $4: 1$ ( $\mathrm{v}: \mathrm{v}$ ) mixture of $\mathrm{HNO}_{3}$ and $\mathrm{HClO}_{3}$ and total $\mathrm{P}$ content was measured by the molybdate-blue method (Murphy \& Riley 1962) on a Technicon Autoanalyser II (Technicon Autoanalysers; Analytical Instruments Recycle, Inc., Golden, CO, USA). The ${ }^{32} \mathrm{P}$ contents were measured in a Packard 1900TR liquid scintillation counter (Packard Instrument Co., Meriden, CT, USA). Root samples were cleared and stained for AM fungal colonization using the method of 
Phillips \& Hayman (1970), omitting phenol from the reagents and $\mathrm{HCl}$ from the rinse. Total root length was determined using a line-intercept method (Newman 1966) and the proportion of the root length colonized by AM fungi was assessed simultaneously. Hyphae were extracted from 2-g soil samples from the side arm soil, collected on membrane filters and total lengths were measured by a grid-line intercept technique (Jakobsen et al.1992b).

\section{Experiment 2}

The purpose was to contrast the effects of mycorrhizas of the $\mathrm{P}$ uptake and growth of $b r b$ and its wild type plants at a range of soil P. Plants were grown in ConeTainers ${ }^{\circledR}$ (Stuewe and Sons, Inc., Corvallis, OR, USA) filled with $750 \mathrm{~g}$ of the soil-sand mixture described under experiment 1 and with $\mathrm{KH}_{2} \mathrm{PO}_{4}$ mixed into the soil at the rates $0,1,2$, $3,4,6,8,10,13,16,20,25,30,40$ and $80 \mathrm{mg} \mathrm{P} \mathrm{kg}^{-1}$ soil. Each of the $15 \mathrm{P}$ levels had four treatments ( $\mathrm{brb} /$ wild type barley $\times$ AM fungal inoculation/no inoculation), which were not replicated. Inoculum was a mixture of two AM fungi, Glomus claroideum (Schenck \& Smith) emend. Walker \& Vestberg (V248) and G. intraradices Schenck \& Smith (DAOM 197198; Biosystematics Research Centre, Ottawa, Canada) originating from separate pot cultures. Inoculated pots had $75 \mathrm{~g}$ of the growth medium replaced by $75 \mathrm{~g}$ inoculum. No further $\mathrm{P}$ was added to inoculated pots to compensate for the lower $\mathrm{P}$ contents in the pot culture soil than in the $\mathrm{P}$-amended treatments and soil $\mathrm{P}$ contents were therefore lower in mycorrhizal treatments. This missing $\mathrm{P}$ supply was $6 \mathrm{mg} \mathrm{P}$ pot $^{-1}$ at the $80 \mathrm{mg} \mathrm{P} \mathrm{kg}^{-1}$ treatment. A total of $70 \mathrm{mg} \mathrm{N}$ was added periodically to each pot as $\mathrm{NH}_{4} \mathrm{NO}_{3}$ solution. Pots were harvested after $20 \mathrm{~d}$ and dry matter production, $\mathrm{P}$ concentration in shoots and roots, root length and colonized root length were determined as described under experiment 1.

\section{Experiment 3}

The purpose was to compare the ability of seven AM fungi to functionally replace root hairs in terms of $\mathrm{P}$ uptake ability and plant growth. The two genotypes were grown in ConeTainers $^{\circledR}$ with $750 \mathrm{~g}$ of the nutrient-amended soil-sand substrate described above and without any additional $\mathrm{P}$ supply. Each genotype had eight inoculation treatments:
No inoculum, Gigaspora rosea (BEG 9), Scutellospora calospora (Nicol. \& Gerd.) Walker and Sanders (BEG 43), Glomus caledonium (Nicol. \& Gerd.) Trappe and Gerdemann (BEG 20), G. mosseae (Nicol. \& Gerd.) Gerdemann \& Trappe, isolates 1 (V293) and 2 (BEG 161), G. claroideum (V12) and G. intraradices (BEG 87). Inoculated pots had $75 \mathrm{~g}$ of the $750 \mathrm{~g}$ soil-sand mixture replaced by $75 \mathrm{~g}$ inoculum. A total of $80 \mathrm{mg} \mathrm{N}$ was added periodically to each pot as $\mathrm{NH}_{4} \mathrm{NO}_{3}$ solution. Plants were harvested after $28 \mathrm{~d}$ and root and shoot samples were analysed as described above.

\section{Statistical analysis}

Data from experiments 1 and 3 were subjected to two-way ANOVA to compare mycorrhizal status and barley genotypes using GenStat for PC/Windows 6.1 (Payne 2002). Multi-comparisons were applied to experiment 3 data using least significant difference (LSD) at the $5 \%$ level in order to compare means of inoculation treatments across genotypes, where genotype and inoculation interacted, or within each genotype where there were no significant interactions. Linear and non-linear regression (curve fitting), and curve comparison by $F$-test were completed using GRAPHPAD PRISM version 4.02 for windows (GraphPad Software, San Diego CA, USA; http://www.graphpad.com). Comparison of equation parameters of non-linear regression curves was done by comparing $95 \%$ confidence intervals or by comparing standard errors of best curve fit (Motulsky 1999).

\section{RESULTS}

\section{Formation and function of mycorrhizas in brb mutant (experiment 1)}

The roots of the mutant developed extensive mycorrhizas in association with $G$. mosseae; as much as $67 \%$ of the root length was colonized at $28 \mathrm{~d}$ and the root-free hyphal compartment (HC) contained $4 \mathrm{~m}$ hyphae per g soil (Table 1). The $G$. mosseae colonization of roots and soil was considerably less in wild-type plants $(P<0.001)$. However, the fungus developed arbuscules in the inner layers of cortex cells of both genotypes, which also showed no obvious structural differences in their formation of distinctive epidermis, cortex, endodermis and vascular cell layers (Fig. 1).

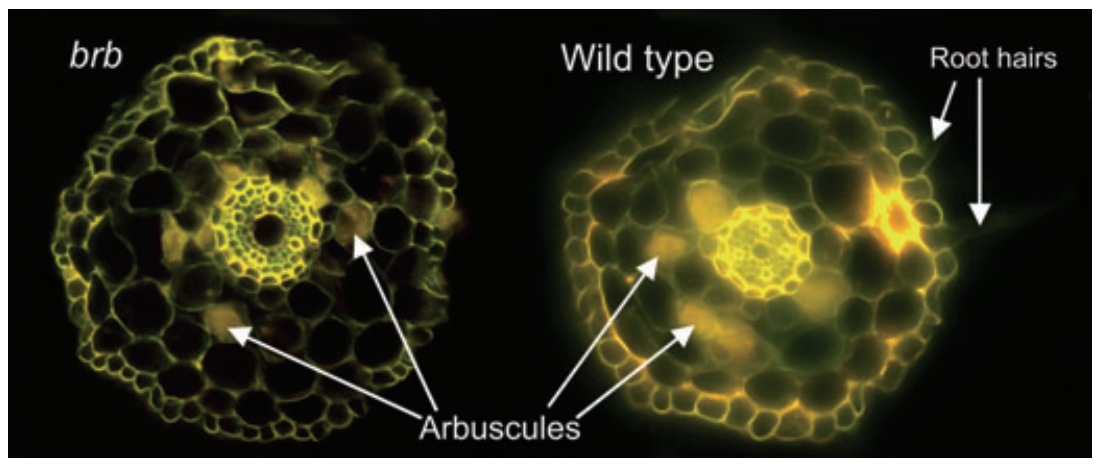

Figure 1. Cross sections of G. mosseaecolonized roots of 28-day-old $b r b$ and wildtype barley plants. Roots of $b r b$ are completely bald whereas root hairs are present on wild-type roots. Metabolically active arbuscules are present in both genotypes. Experiment 1. 
Table 1. Mycorrhiza formation (colonized root length and hyphal length density in $\mathrm{HC}$ soil), dry matter production, $\mathrm{P}$ content and $\mathrm{P}$ uptake from $\mathrm{HC}$ soil in $H$. vulgare plants (means $\pm \mathrm{SEM})$. Both the brb mutant and the wild type $(\mathrm{Wt})$ were inoculated with $G$. mosseae $(+\mathrm{M})$ or left uninoculated $(-\mathrm{M})$. Plants were harvested after $28 \mathrm{~d}$. (Experiment 1$)$

\begin{tabular}{|c|c|c|c|c|c|c|c|}
\hline \multirow[b]{3}{*}{ Genotype } & \multirow[b]{3}{*}{ Inoculation } & \multicolumn{2}{|c|}{ Mycorrhiza formation } & \multirow{3}{*}{$\begin{array}{l}\text { Dry weight } \\
\left(\mathrm{g} \mathrm{pot}^{-1}\right)\end{array}$} & \multirow{3}{*}{$\begin{array}{l}\text { P content } \\
\left(\text { mg plant }^{-1}\right)\end{array}$} & \multirow{2}{*}{\multicolumn{2}{|c|}{$\mathrm{P}$ uptake from $\mathrm{HC}^{\mathrm{c}}$}} \\
\hline & & \multirow{2}{*}{$\begin{array}{l}\text { Colonization }{ }^{\mathrm{a}} \\
\text { (\% root length) }\end{array}$} & \multirow{2}{*}{$\begin{array}{l}\text { HC hyphae } \\
\left(\mathrm{m} \mathrm{g}^{-1} \text { soil }\right)\end{array}$} & & & & \\
\hline & & & & & & $\left(\mathrm{mg} \operatorname{pot}^{-1}\right)$ & (\% of total) \\
\hline$b r b$ & $-\mathrm{M}$ & 0 & 0 & $0.84 \pm 0.10$ & $1.22 \pm 0.13$ & 0 & 0 \\
\hline$b r b$ & $+\mathrm{M}$ & $67 \pm 2.9$ & $4.0 \pm 1.2$ & $1.23 \pm 0.16$ & $2.15 \pm 0.25$ & $1.42 \pm 0.15$ & $67 \pm 11.7$ \\
\hline Wt & $-\mathrm{M}$ & 0 & 0 & $3.57 \pm 0.16$ & $4.72 \pm 0.23$ & $0.17 \pm 0.01$ & $4 \pm 0.3$ \\
\hline Wt & $+\mathrm{M}$ & $16 \pm 6.1$ & $1.8 \pm 1.0$ & $2.97 \pm 0.36$ & $3.91 \pm 0.52$ & $0.40 \pm 0.18$ & $11 \pm 4.1$ \\
\hline LSD & & 6.0 & 1.4 & 0.38 & 0.54 & 0.23 & 14.3 \\
\hline \multicolumn{8}{|l|}{ Significance $^{\mathrm{d}}$ of } \\
\hline Genotype & & $* * *$ & $*$ & $* * *$ & $* * *$ & $* * *$ & $* * *$ \\
\hline Inoculation & & $* * *$ & $* * *$ & NS & NS & $* * *$ & $* * *$ \\
\hline Genotype $\times$ inoculation & & $* * *$ & $*$ & $*$ & $* *$ & $* * *$ & $* * *$ \\
\hline
\end{tabular}

${ }^{\mathrm{a}}$ Roots in RC adjacent to HC. ${ }^{\mathrm{b}}$ Normalized for background in $\mathrm{HC}$ of non-mycorrhizal pots $\left(2.3 \mathrm{~m} \mathrm{~g} \mathrm{soil}{ }^{-1}\right)$. ${ }^{\mathrm{c}} \mathrm{Calculated}$ from the ${ }^{32} \mathrm{P}$ content

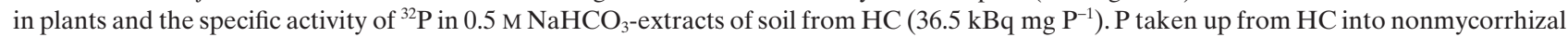
brb plants $\left(0.19 \mathrm{mg} \mathrm{P} \mathrm{pot}^{-1}\right)$ was considered as diffusion and was subtracted. ${ }^{\mathrm{d}} \mathrm{By}$ analysis of variance, ${ }^{* * *}, P<0.001 ; * *, P<0.01 ; *, P<0.05$; NS, not significant.

Root hairs were never observed in the mutant in this or in the subsequent experiments. Wild-type plants grew larger than the mutant and differences in dry weights between treatments were generally reflected in the $\mathrm{P}$ contents of the plants. One major difference between plant genotypes was that $G$. mosseae increased P uptake and growth of the brb mutant whereas the biomass of wild-type plants was less in the presence than in the absence of mycorrhizas (Table 1). The $\mathrm{P}$ uptake by root hairs growing through the nylon mesh into the ${ }^{32} \mathrm{P}$-labelled $\mathrm{HC}$ soil was quantified by subtracting the HC-derived $\mathrm{P}$ present in $b r b$, NM plants from the uptake into wild-type, NM plants. The root hair uptake was small and similar to the amount of $\mathrm{P}$, which had diffused through the nylon mesh and been absorbed by the hairless $b r b$ roots (Table 1). In contrast, G. mosseae hyphae growing from colonized $b r b$ roots into the $\mathrm{HC}$ soil acquired as much as $1.42 \mathrm{mg} \mathrm{P}$ or $67.3 \%$ of the total plant $\mathrm{P}$ content. The association of $G$. mosseae and wild-type barley acquired only $0.40 \mathrm{mg} \mathrm{P}$ from $\mathrm{HC}$ soil in agreement with a lower length density of hyphae in the $\mathrm{HC}$ soil. Consequently, the $\mathrm{P}$ uptake per hyphal length unit, taken as an overall average, differed less between the wild type and the mutant (4.4 versus $2.8 \mu \mathrm{g} \mathrm{P} \mathrm{m}^{-1}$ hyphae) than did the contrasting amounts of total $\mathrm{P}$ derived from $\mathrm{HC}$.

\section{Modulation of $\mathbf{P}$ response curves by root hairs and by mycorrhizas (experiment 2)}

Roots of both $b r b$ mutant and wild-type plants had become colonized by the AM fungi after 3 weeks (Fig. 2a). At each level of $\mathrm{P}$ supply, roots of the mutant were always the most heavily colonized with levels ranging from nearly $70-80 \%$ of the root length at nil $\mathrm{P}$ supply to $10 \%$ at the highest $\mathrm{P}$ supply. Correspondingly, colonization of roots of inoculated wild-type plants decreased from about $50 \%$ to only $2 \%$ with increasing level of P supply (Fig. 2a). Hence, the percentage root length colonized was plotted against plant growth expressed as percentage of maximum shoot growth and the resulting decrease in root colonization with increasing plant size was described by linear regressions with nonsignificant differences in slopes and $y$-intercepts between genotypes (Fig. 2b).

Growth of non-mycorrhizal brb barley was very poor at the low levels of P supply and plant dry weight increased dramatically with increasing P supply (Fig. 3a). Growth of non-mycorrhizal, wild-type barley responded less to additional $\mathrm{P}(P<0.0001)$ and dry weights of the two genotypes converged at the highest $\mathrm{P}$ supplies. The two response curves for P uptake of non-mycorrhizal genotypes had similar slopes, but the uptake was significantly lower in $b r b$ than in the wild type (Fig. 3c). The response curves for dry weights of mycorrhizal plants were similar to those of nonmycorrhizal plants except that mycorrhizal brb plants grew significantly better at the low $\mathrm{P}$ supply range than their non-mycorrhizal counterparts (Fig. 3a versus 3b). Mycorrhizas modulated the response curves for $\mathrm{P}$ uptake in $b r b$ plants by significantly increasing the uptake at the lowerend $\mathrm{P}$ supply range (Fig. 3d). The response curve for $\mathrm{P}$ uptake of wild-type plants was not significantly affected by mycorrhizas.

The root length-specific $\mathrm{P}$ uptake in non-mycorrhizal plants was clearly depressed by the absence of root hairs, but curves differed significantly and had overlapping confidence intervals at nil P supply (Fig. 4a). Mycorrhizas significantly altered response curves for root length-specific $\mathrm{P}$ uptake in both $b r b$ and wild type, but the $y$-intercept was significantly increased in brb only (Fig. 4a versus 4b).

Total biomass production as a function of shoot $\mathrm{P}$ concentration generally increased towards a maximum plateau, but curve shapes were influenced by both root hairs and mycorrhiza (Fig. 5). Over a range of shoot $\mathrm{P}$ concentrations, non-mycorrhizal wild-type plants utilized $\mathrm{P}$ more effec- 

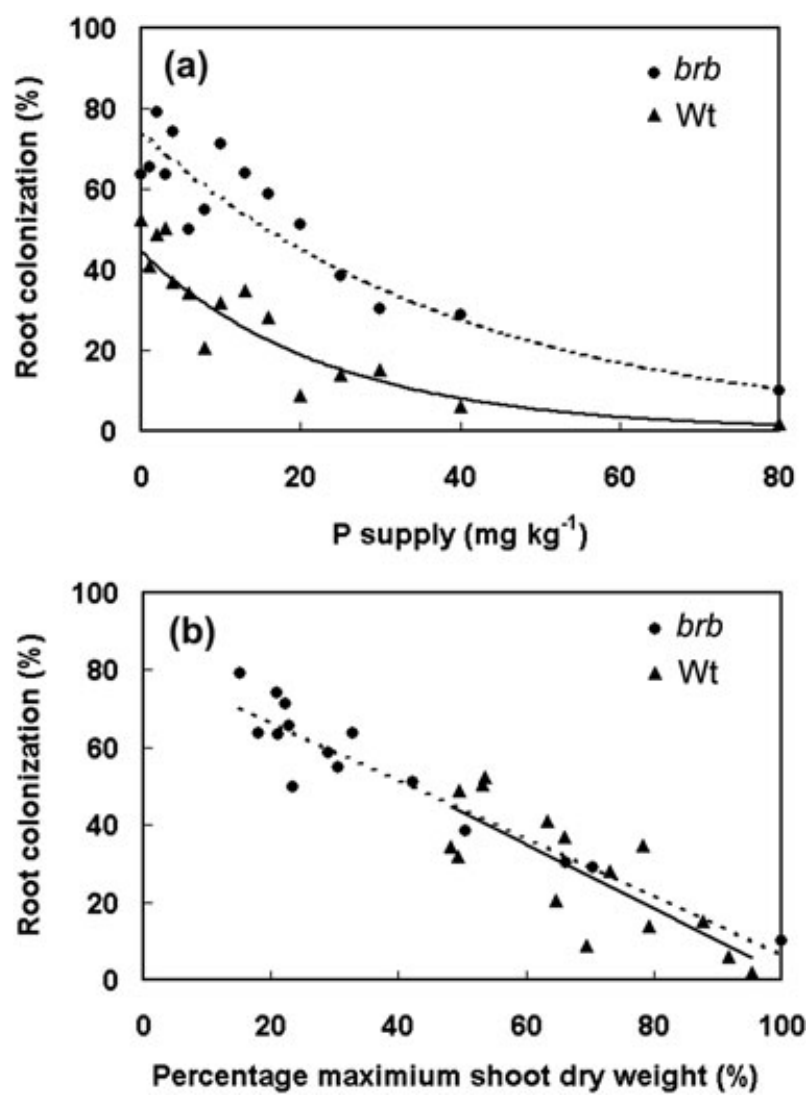

Figure 2. Mycorrhiza formation in 21-day-old $b r b$ and wild-type barley (Wt) grown in association with a mixture of G. claroideum and G. intraradices at 15 levels of P supply. (a) Percentage of root length colonized in each plant genotype as a function of P supply; curve fitting by exponential model for $b r b$ (broken line, $y=$ $\left.74.03 \mathrm{e}^{-0.0246 x} ; R^{2}=0.93, P<0.0001\right)$ and $\mathrm{Wt}$ (solid line, $y=$ $\left.44.54 \mathrm{e}^{-0.0427 x} ; R^{2}=0.90, P<0.0001\right)$. Significant difference between curves at $y$-intercepts (95\% confidence intervals). (b) Percentage of root length colonized as a function of plant size, expressed as percentage of maximum shoot growth; curve fitting by linear model for $b r b$ (broken line, $y=-0.752 x+81.911 ; R^{2}=0.90$, $P<0.0001$ ) and Wt (solid line, $y=-0.834 x+85.201 ; R^{2}=0.64$, $P<0.001)$. Non-significant differences between curves $(95 \%$ confidence intervals for slopes and intercepts). Each symbol represents one plant, $n=1$. Experiment 2 .

tively in biomass production than did their corresponding brb mutant plants (Fig. 5a). This relationship was markedly different for the mycorrhizal brb plants, where shoot $\mathrm{P}$ concentrations in 14 of 15 treatments fell within a relatively narrow range (2.4-3.1 $\mathrm{mg} \mathrm{P} \mathrm{g}^{-1}$ dry weight) (Fig. 5b). Furthermore, 10 of the shoot $\mathrm{P}$ concentrations in this range resulted in a dry weight production in brb which, on average was only $37 \%$ of the dry weights in the three other treatments with shoot $\mathrm{P}$ concentrations within the same range.

\section{The relative importance of root hairs and different mycorrhizal fungi (experiment 3)}

All inoculated plants had $60-80 \%$ of their total root length colonized in associations involving Gi. rosea and the five
Glomus isolates (Fig. 6a). Plants associated with $S$. calospora differed by their lower percentage root colonization and by lower colonization in the wild type than in the $b r b$ plants. Non-inoculated plants remained uncolonized throughout the experiment. The specific root length was higher in $b r b$ than in wild-type plants $(P<0.01)$ and was in most cases lower in mycorrhizal than in non-mycorrhizal plants (Fig. 6b).

Non-mycorrhizal brb plants grew poorly in comparison with their wild-type counterparts (Fig. 7a). However, growth of $b r b$ was increased by six of the seven AM fungal inocula, and in three associations (G. caledonium and the two G. mosseae isolates), total dry weights were similar to those of non-mycorrhizal, wild-type plants. One of the $G$. mosseae isolates fully substituted root hairs in the support of plant growth. Dry weights of $b r b$ were not increased by $S$. calospora. The total $\mathrm{P}$ uptake of the brb plants was increased by all AM fungi and the five Glomus isolates led to considerably higher $\mathrm{P}$ uptakes than were present in the non-mycorrhizal wild type (Fig. 7b). Root colonization by these five fungi therefore resulted in a higher $\mathrm{P}$ acquisition than that obtained with root hairs. The $\mathrm{P}$ uptake by brb roots associated with Gi. rosea was as effective as that of wild-type barley with root hairs.

The wild-type plants showed similar dry matter production in all treatments and only G. intraradices and G. mosseae 1 enhanced growth beyond that of uninoculated plants (Fig. 7a). All associations between wild-type plants and the seven AM fungi had acquired more $\mathrm{P}$ than the non-mycorrhizal plants, but the $\mathrm{P}$ uptake varied between the fungi (Fig. 7b). The mycorrhiza-induced enhancements of $\mathrm{P}$ uptake in wild-type plants had no marked effects on growth.

$B r b$ and wild-type plants differed only marginally in $\mathrm{P}$ uptake when associated with any of the five Glomus species (Fig. 7b) and $\mathrm{P}$ uptake expressed on the basis of a root length unit was not significantly influenced by plant genotype (Fig. 7c). In non-mycorrhizal plants, root lengthspecific P uptake was clearly lower in brb than in the wild type. In contrast, mycorrhizas increased root length-specific P uptake for each barley genotype, except for plants colonized by S. calospora (Fig. 7c). The specific P uptake varied less with AM fungal isolate in wild type than in $b r b$ mutant plants.

\section{DISCUSSION}

This work provides the hitherto strongest evidence for the suggestion that root hairs and arbuscular mycorrhizas are alternative means of root uptake of $\mathrm{P}$ that is not readily available at the root surface (Baylis 1970). The progress can be ascribed to our use of the root hairless monogenic mutant and its wild type, a plant model system, which is superior to those used in previous studies comparing species or cultivars differing in root hair length (Baylis 1970; Baon et al. 1994; Schweiger et al. 1995). Our results led to the overall acceptance of the working hypotheses: (1) the 


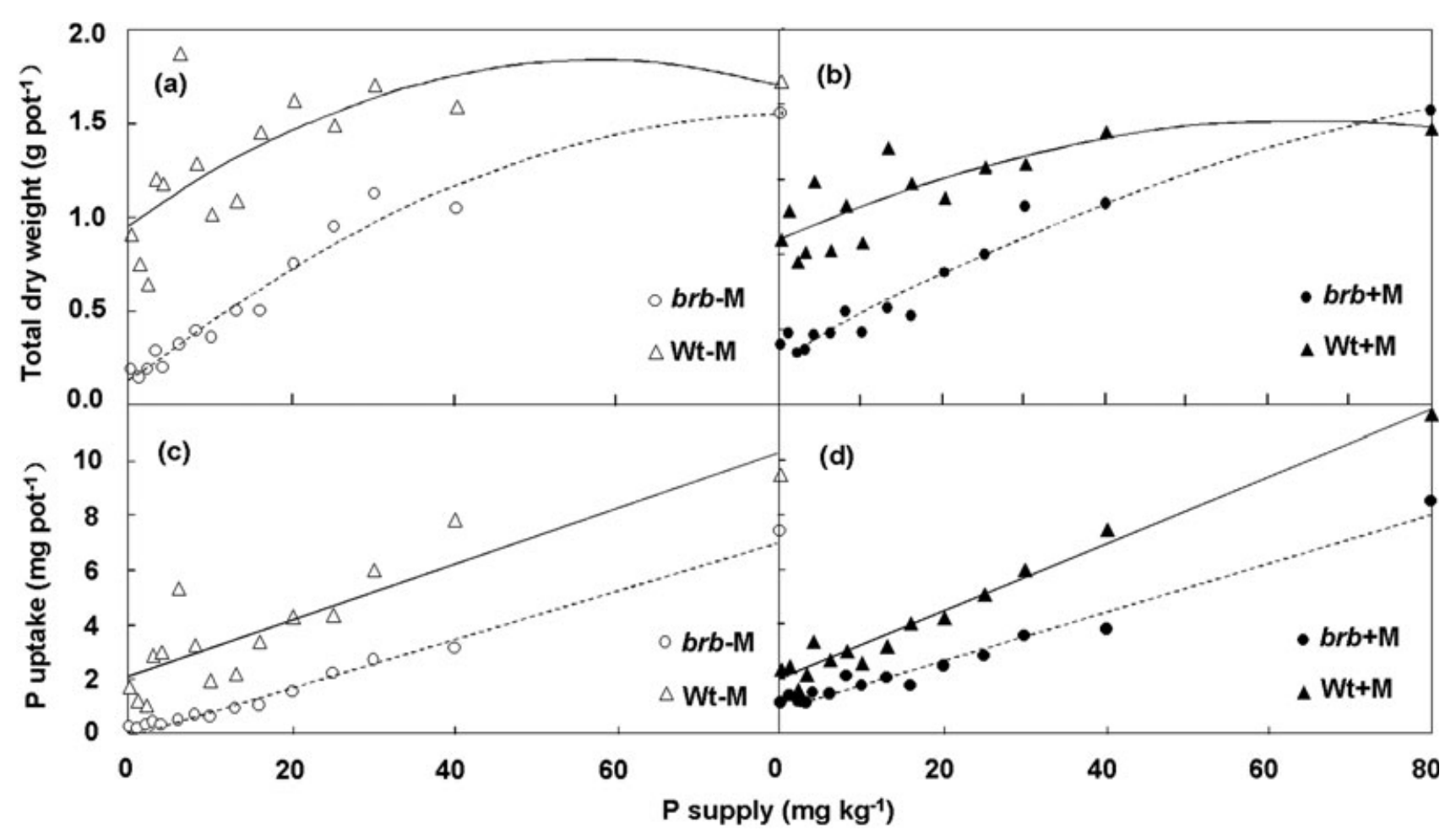

Figure 3. Total dry weight and $\mathrm{P}$ uptake of 21-day-old brb and wild-type (Wt) barley plants grown at $15 \mathrm{P}$ levels without AM fungal inoculation or in association with a mixture of G. claroideum and G. intraradices. Curve fittings by quadratic model for dry weight and by linear model for P uptake. (a) Dry weight, non-mycorrhizal (-M) $b r b$ (broken line), $y=-0.0002 x^{2}+0.0343 x+0.1211\left(R^{2}=0.97, P<0.0001\right)$; $(-\mathrm{M}) \mathrm{Wt}$ (solid line), $y=-0.0003 x^{2}+0.0303 x+0.9703\left(R^{2}=0.51, P<0.05\right)$; (b) Dry wt, mycorrhizal $(+\mathrm{M}) b r b$ (broken line), $y=$ $-0.0001 x^{2}+0.0304 x+0.3145\left(R^{2}=0.96, P<0.0001\right) ;+\mathrm{M} \mathrm{Wt}$ (solid line), $y=-0.0002 x^{2}+0.0244 x+1.0910\left(R^{2}=0.67, P<0.01\right) ;(\mathrm{c}) \mathrm{P}$ uptake, -M brb (broken line), $y=0.0891 x-0.0608\left(R^{2}=0.99, P<0.0001\right) ;-\mathrm{M} \mathrm{Wt}$ (solid line), $y=0.1033 x+2.0830\left(R^{2}=0.79, P<0.001\right)$; (d) P uptake, $+\mathrm{M}$ brb (broken line), $y=0.0887 x+0.8808\left(R^{2}=0.97, P<0.0001\right) ;+\mathrm{M} \mathrm{Wt}$ (solid line), $y=0.1231 x+1.9908\left(R^{2}=0.97, P<0.001\right)$. The following dry weight curves differed significantly ( $F$-test, $P<0.0001)$ : $-\mathrm{M}$ brb versus $\mathrm{Wt},+\mathrm{M}$ brb versus $\mathrm{Wt}$, and $b r b,-\mathrm{M}$ versus $+\mathrm{M}$; curves for $\mathrm{Wt}-\mathrm{M}$ versus $+\mathrm{M}$ did not differ $(P=0.81)$. Intercepts of fitted $\mathrm{P}$ uptake curves for $-\mathrm{M} b r b$ versus Wt differed $(F$-test, $P<0.0001)$, whereas differences between slopes were non-significant $(P=0.35)$. Slopes of $\mathrm{P}$ uptake curves for $+\mathrm{M} b r b$ versus Wt differed $(P<0.0001)$. Intercepts of $\mathrm{P}$ uptake curves differed $(P<0.0001)$ for $b r b-\mathrm{M}$ versus $+\mathrm{M}$, but slopes $\operatorname{did} \operatorname{not}(P=0.94)$. Differences for $\mathrm{Wt}-\mathrm{M}$ versus $+\mathrm{M}$ were nonsignificant for both slopes $(P=0.22)$ and intercepts $(P=0.45)$. Each symbol represents one plant, $n=1$. Experiment 2 .

$b r b$ root hairless mutant developed functional arbuscular mycorrhizas upon inoculation with an AM fungus; (2) one mycorrhizal fungus was able to counterbalance growth depressions of the root hairless mutant at low soil P levels; and (3) the ability of mycorrhizas to substitute for root hairs varied markedly among AM fungi.

\section{Formation and function of mycorrhizas in the brb mutant}

Mycorrhizas developed rapidly in the brb mutant plants in all three experiments and as much as $80 \%$ of the root length had become colonized after 3-4 weeks growth in soil given no additional $\mathrm{P}$. Levels of colonization at individual $\mathrm{P}$ supplies were higher in mutant than in wild-type plants in experiments 1 and 2 and this difference was most likely caused by differences in plant $\mathrm{P}$ status being a major determinant of mycorrhiza formation (Sanders 1975; Graham, Leonard \& Menge 1981; Thomson, Robson \& Abbott 1991). Accordingly, differences between $b r b$ and wild-type plants disappeared when colonization levels were normalized for differences in shoot growth (Fig. 2b). Mycorrhiza formation can also be limited by severe P deficiency, such that maximum colonization is reached at moderate $\mathrm{P}$ deficiency (Bolan, Robson \& Barrow 1984). This may explain why percentage colonization of brb roots in experiment 2 tended to reach a maximum at a $\mathrm{P}$ supply of $2 \mathrm{mg} \mathrm{P} \mathrm{kg}^{-1}$ soil and why intergenotype difference in colonization was less marked at nil $\mathrm{P}$ supply, in both experiments 2 and 3 . An exception to this similarity in colonization of $b r b$ and wild-type roots in experiment 3 was seen in the S. calospora treatment and this confirms the functional diversity of these associations (Smith et al. 2000). The poorer mycorrhiza formation by wild-type plants in experiment 1 than at equivalent $\mathrm{P}$ supplies (OP) in experiments 2 and 3 may be related to the better plant growth in experiment 1 .

Analysis of cross-sections of colonized roots showed that mycorrhizal structures, including arbuscules, became well established in the root cortex of both barley genotypes. The overall similarity in root anatomy between the $b r b$ mutant 


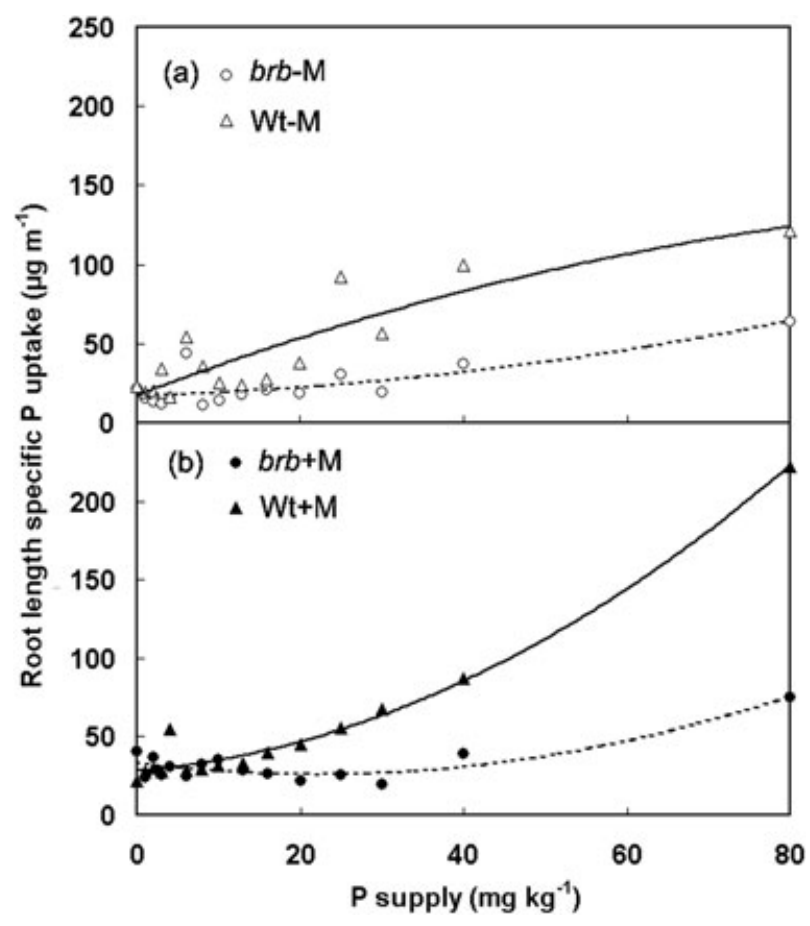

Figure 4. Root length specific P uptake in 21-day-old brb and wild-type (Wt) barley grown at 15 levels of P supply. (a) Plants grown without AM fungal inoculation. (b) Plants grown in association with a mixture of G. claroideum and G. intraradices. Curve fitting by quadratic model: non-mycorrhizal $(-\mathrm{M}) b r b$ (broken line), $y=0.0056 x^{2}+0.1422 x+17.2552$ $\left(R^{2}=0.68, P<0.01\right) ;-\mathrm{M} \mathrm{Wt}$ (solid line), $\mathrm{y}=$ $-0.0077 x^{2}+1.9454 x+17.7513\left(R^{2}=0.78, P<0.001\right)$; mycorrhizal (+M) $b r b$ (broken line), $y=0.0148 x^{2}-0.6495 x+33.0401$ $\left(R^{2}=0.83, P<0.0001\right) ;+\mathrm{M} \mathrm{Wt}$ (solid line), $y=0.0251 x^{2}+0.4290 x+28.3887\left(R^{2}=0.98, P<0.0001\right)$. Curves differed significantly by $F$-test: $-\mathrm{M}$ brb versus Wt and $+\mathrm{M} b r b$ versus Wt $(P<0.0001), b r b-\mathrm{M}$ versus $+\mathrm{M}(P=0.0117)$, and Wt $\mathrm{M}$ versus $+\mathrm{M}(P=0.0002)$. Each symbol represent one plant, $n=1$. Experiment 2.

and the wild type confirms previous results (Gahoonia et al. 2001; Gahoonia \& Nielsen 2003).

Environmental factors influence root architecture including root fineness or specific root length (SRL), which is usually inversely related to soil $\mathrm{P}$ availability and reduced by mycorrhiza (Berta, Fusconi \& Trotta 1993; Zhu, Smith \& Smith 2003). Accordingly, the present work showed that SRL was smaller in wild-type plants than in $b r b$, in particular in the absence of mycorrhizas, and SRL was in most cases lower in mycorrhizal than in non-mycorrhizal plants. The effect of AM fungi on root fineness may be caused by differences in nutrition status, but it appears that direct effect of mycorrhiza-induced blocking of meristem activity has greater importance (Fusconi et al. 2000).

\section{Relative importance of root hairs and mycorrhizas in $\mathbf{P}$ acquisition ability}

P uptake from root free soil by non-mycorrhizal, wild-type plants in experiment 1 was twice the uptake by correspond- ing $b r b$ plants. This reflects the enhancement in uptake by hairy roots over that of hairless roots, and is in accordance with the observation of wider $\mathrm{P}$ depletion zones in wildtype than in brb plants (Gahoonia \& Nielsen 2003). Mycorrhizal $b r b$ roots exhibited nearly an order of magnitude greater $\mathrm{P}$ acquisition than comparable non-mycorrhizal roots with root hairs (i.e. wild type), which can be attributed to the longer extension of hyphae than root hairs into undepleted soil (Joner et al. 1995).

The observed depression in $\mathrm{P}$ uptake by root hairless non-mycorrhizal plants grown at low $\mathrm{P}$ supplies is in accordance with the previous finding by Gahoonia \& Nielsen (2003) using the same experimental soil, which in our case was diluted with sand and irradiated to eliminate indigenous AM fungi. The loss of root hairs clearly changed the barley from being a moderate to a strong responder to $\mathrm{P}$. However, the present work demonstrates that inoculation with mycorrhizal fungi restored $\mathrm{P}$ uptake in $b r b$. This effect

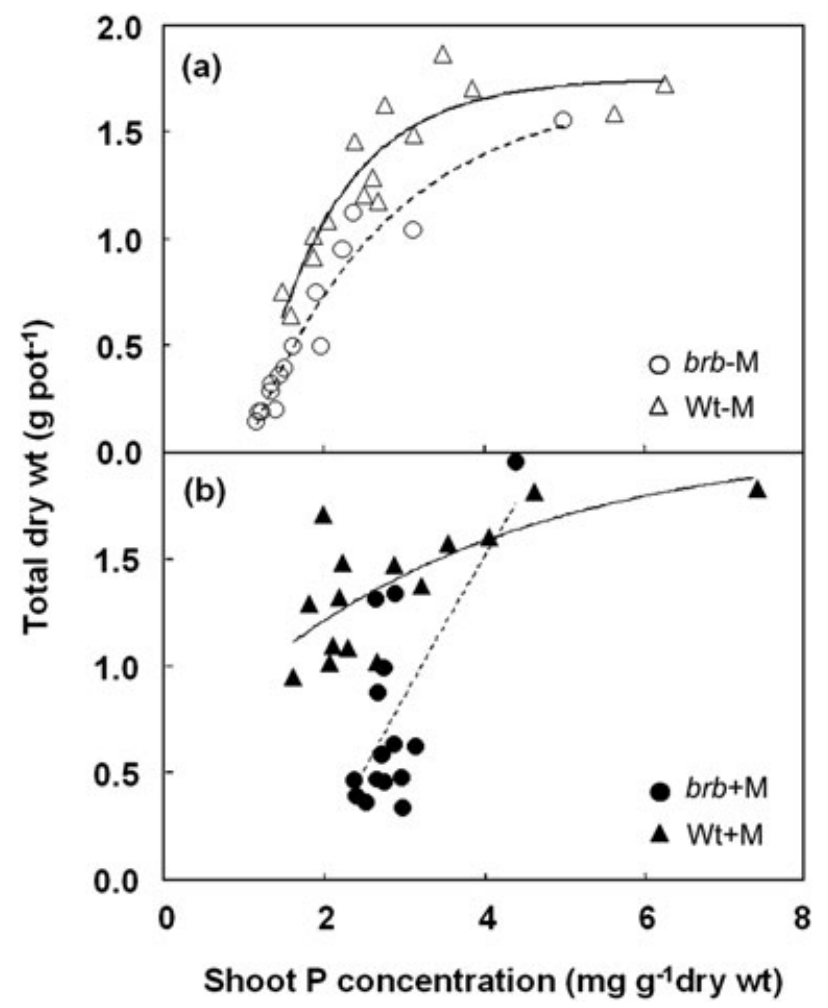

Figure 5. Relationship between total dry wt. and shoot $\mathrm{P}$ concentration of 21-day-old $b r b$ and wild-type (Wt) barley grown at 15 levels of P supply. (a) Plants grown without AM fungal inoculation. (b) Plants grown in association with a mixture of $G$. claroideum and $G$. intraradices. Curve fitting by one phase exponential association model: non-mycorrhizal (-M) brb, $y=3.07\left(1-\mathrm{e}^{-0.58 x}\right)-1.37\left(R^{2}=0.94, P<0.0001\right) ;-\mathrm{M} \mathrm{Wt}$, $y=4.87\left(1-\mathrm{e}^{-0.99 x}\right)-3.12\left(R^{2}=0.86, P<0.0001\right) ;$ mycorrhizal $(+\mathrm{M})$ brb, $y=12.83\left(1-\mathrm{e}^{-0.064 x}\right)-1.37\left(R^{2}=0.46, P<0.05\right)$; $+\mathrm{M} \mathrm{Wt}$, $y=1.51\left(1-\mathrm{e}^{-0.29 x}\right)+0.55\left(R^{2}=0.51, P<0.001\right)$. Pair-wise comparisons of treatments revealed significant differences $(95 \%$ confidence intervals) between slopes for $-\mathrm{M} b r b$ versus Wt and between Y-intercepts for $+\mathrm{M} b r b$ versus Wt and $b r b-\mathrm{M}$ versus $+\mathrm{M}$ (log-transformed data). Each symbol represent one plant, $n=1$. Experiment 2. 


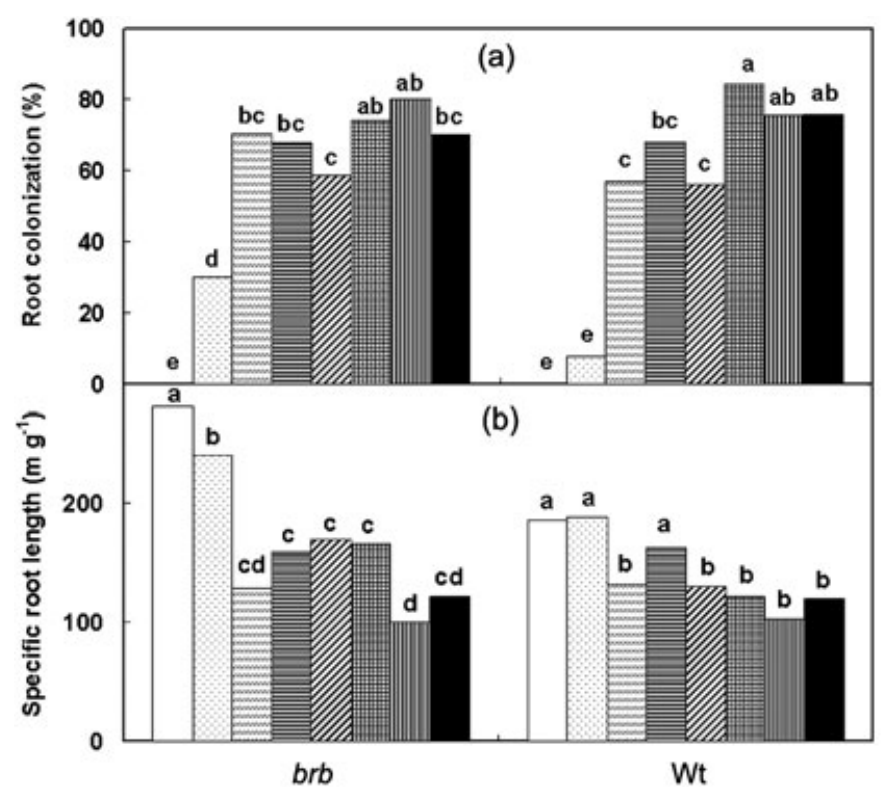

of mycorrhizal inoculation was already obvious after a 3week-growth period although $\mathrm{P}$ uptake by mycorrhizal fungi established from a crude soil inoculum as used is usually not detectable in the host plant until 10-15 d after sowing (Cavagnaro et al. 2005). This increased $\mathrm{P}$ uptake by brb plants in response to inoculation was even larger in experiment 3 where the five Glomus inocula resulted in a $50-130 \%$ greater $\mathrm{P}$ uptake by 4 -week-old $b r b$ plants than that of non-mycorrhizal, wild-type plants.

The importance of root hairs for P uptake was confirmed by the root length-specific $\mathrm{P}$ uptake, which was also lower

\author{
$\square-M$ \\ $\square$ Sc. calospora \\ $\boxminus$ Gi. rosea \\ 日. caledonium \\ G. claroideum \\ I G. intraradices \\ II G. mosseae 1 \\ - G. mosseae 2
}

Figure 6. (a) Percentage colonized root length of $b r b$ and wild-type (Wt) barley grown without mycorrhizas $(-\mathrm{M})$ or in association with seven different AM fungi. (b) Specific root length of the same 16 treatments. By analysis of variance, inoculation was highly significant for both root colonization and specific root length $(P<0.001)$. Genotype was highly significant for specific root length only $(P<0.01)$, and the interaction of genotype with inoculation was significant for root colonization only $(P<0.05)$. Different letters above columns indicate significant differences among inoculation treatments across genotypes (a) or of the same genotype (b) by LSD multicomparison at the $5 \%$ level. $n=3$. Experiment 3.

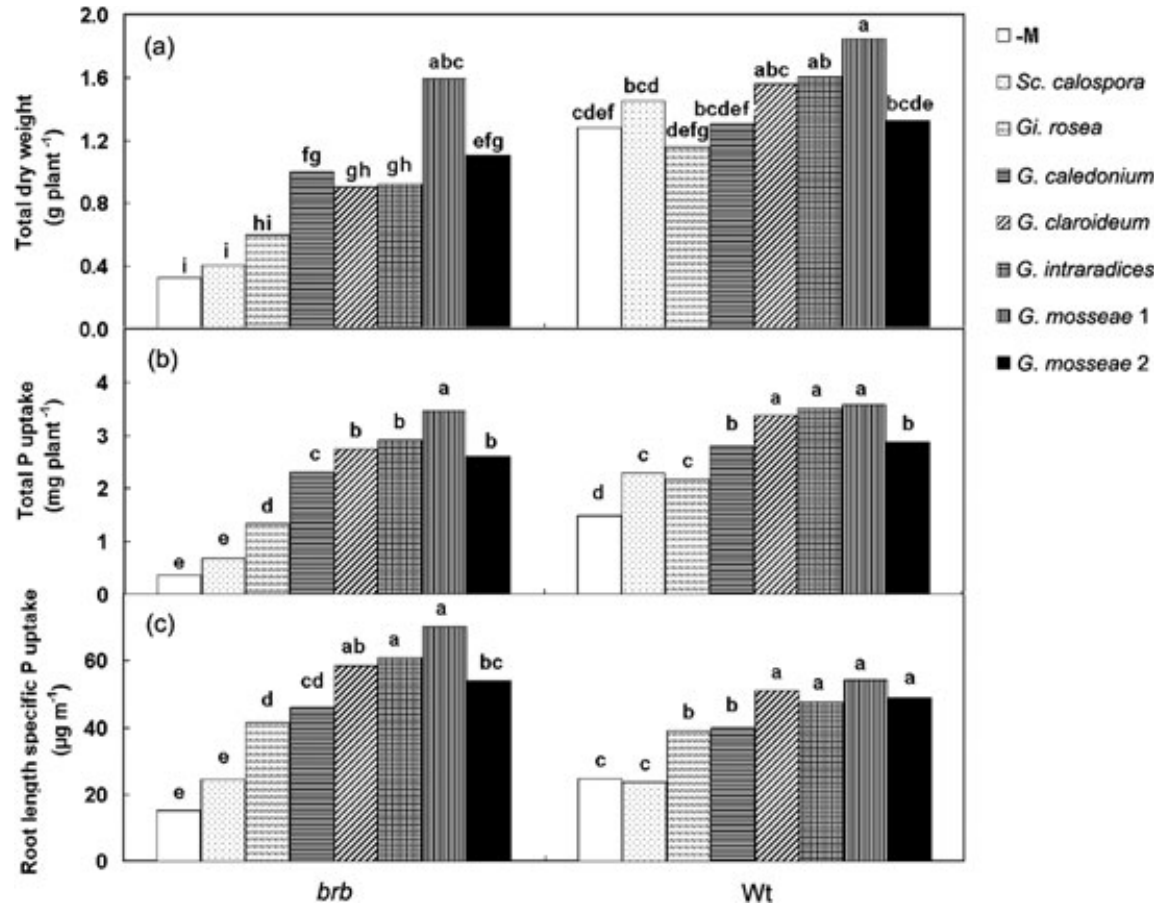

in non-mycorrhizal brb than in wild-type plants, both in experiments 2 and 3 . The rather similar increase in root length-specific $\mathrm{P}$ uptake in response to increasing $\mathrm{P}$ supply in non-mycorrhizal $b r b$ and wild-type plants in experiment 2 confirms the results of Gahoonia \& Nielsen (2003), but was not fully mirrored by the total $\mathrm{P}$ uptake, because of markedly reduced root lengths in $b r b$ plants grown at the lower P supplies (data not shown). Mycorrhizas compensated the low root length-specific P uptake of $b r b$ plants at the lower end of the soil $\mathrm{P}$ regime used in experiment 2 and all seven AM fungi used in experiment 3, where root 
length-specific P uptakes of $b r b$, were similar to or considerably higher than that of non-mycorrhizal wild-type roots.

The direct comparison of root hairs and root external hyphae in the context of $\mathrm{P}$ uptake systems is complicated by the mycorrhiza-induced down-regulation of $\mathrm{P}$ transporters in epidermal cells, including root hairs (Liu et al. 1998; Burleigh, Cavagnaro \& Jakobsen 2002). These transporters are functionally replaced by $\mathrm{P}$ transporters located in arbusculated cortex cells (Rausch et al. 2001; Harrison, Dewbre \& Liu 2002; Paszkowski et al. 2002; Karandashov et al. 2004). Subsequent $P$ uptake studies have shown that plant $\mathrm{P}$ uptake can occur exclusively via the mycorrhizal uptake pathway, even in the absence of an apparent mycorrhizal response in P uptake or growth (Smith et al. 2003). The contribution of the mycorrhizal uptake pathway in wild-type plants in the present work could be calculated for experiment 1 only, where the low mycorrhiza contribution of approximately $7 \%$ of total $\mathrm{P}$ uptake was possibly associated with the relatively sparse root colonization. In contrast, colonization levels of the wild-type and $b r b$ plants in experiment 3 were generally high and in the same range as those in Smith et al. (2003), suggesting a significant contribution via the mycorrhizal pathway. In experiment 3 , the mycorrhizal fungi may therefore have been responsible for a larger proportion of the total $\mathrm{P}$ uptake than suggested by simple subtractions of $\mathrm{P}$ uptake of non-mycorrhizal plants from $\mathrm{P}$ uptake of mycorrhizal plants (see Jakobsen et al. 1992b).

The marked enhancement of P uptake by Gi. rosea, not only in $b r b$ but also in the wild-type barley, is in contrast to more marginal effects of this fungus in previous studies (Smith et al. 2003; Cavagnaro et al. 2005) and confirms the presence of functional diversity in arbuscular mycorrhizas (Jakobsen, Smith \& Smith 2002). It is well known that positive mycorrhizal effects on plant growth and $\mathrm{P}$ uptake are largely influenced by $\mathrm{P}$ accessibility to the plant, which is further determined by root morphology (as demonstrated by experiments 1 and 2). Experiment 3 indicated that compatible fungal strains contribute substantially to $\mathrm{P}$ uptake and growth of a host plant with extensive root hairs (wt barley). The functional diversity and specificity in arbuscular mycorrhiza needs further investigation.

\section{Utilization of $\mathbf{P}$ in biomass production}

Ample amounts of $\mathrm{P}$ provided by AM fungi to the $b r b$ mutant plants in experiments 2 and 3 were generally used less effectively in biomass production than $\mathrm{P}$ acquired by wild-type plants. Only one of seven AM fungi in experiment 3 was highly effective in translating the additional $\mathrm{P}$ uptake into biomass. This is well illustrated by comparing curves for mycorrhizal and non-mycorrhizal brb plants in Fig. 5; however, Fig. 5a shows that a lack of root hairs leads to a decreased P-to-biomass conversion effectiveness. Therefore, the absence of root hairs appears to amplify the less effective use of $\mathrm{P}$ in biomass production in mycorrhizal $b r b$ plants. This fundamental difference in the utilization of $\mathrm{P}$ for plant growth is not directly related to $\mathrm{P}$ acquisition, but perhaps to the need for $\mathrm{P}$ in other processes than growth. A generally delayed $\mathrm{P}$ uptake by hairless roots and a delay from a mycorrhiza-induced increase in $\mathrm{P}$ uptake to its conversion into growth enhancement may also play a role. Hence, a sharp rise in shoot $\mathrm{P}$ concentration at the time of establishment and rapid spread of mycorrhiza was not expressed in increased growth rates until 5-10 d later (Stribley \& Snellgrove 1984). The 21-day-old plants in experiment 2 may have experienced such delay at harvest time, as rapid extension of mycorrhizas does not occur until 10$15 \mathrm{~d}$ after planting at our growth conditions.

Carbon costs of the $\mathrm{P}$ acquisition structures and processes might also have influenced the conversion of absorbed $\mathrm{P}$ into biomass. Root hairs apparently contribute little to overall carbon costs as respiration per unit root length was similar in Arabidopsis wild type and a root hairless mutant (rhd2) grown at low soil P levels (Bates \& Lynch 2000b). In contrast, mycorrhizas may increase below-ground respiration to more than twice that of nonmycorrhizal controls (Jakobsen \& Rosendahl 1990). Carbon use by the AM fungi may thus have contributed to the observed low effectiveness in $\mathrm{P}$ utilization in biomass production of mycorrhizal brb plants grown at low $\mathrm{P}$ conditions. The $\mathrm{P}$ content of these plants is not fully translated into increased growth as observed in the other treatments. In terms of carbon economy, breeding for longer and denser root hairs would therefore seem more attractive than breeding for more extensive mycorrhiza development. Root hairs do not grow as long as the potential $10-15 \mathrm{~cm}$ extension of the root-external mycelium of AM fungi ( $\mathrm{Li}$, George \& Marschner 1991; Jansa, Mozafar \& Frossard 2003) and plants with low root length densities where

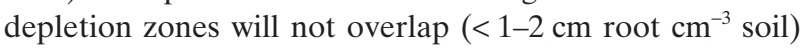
will still depend on the AM fungi to access the soil $\mathrm{P}$ present outside $\mathrm{P}$ depletion zones.

\section{CONCLUSIONS}

This study made use of a root hairless barley mutant to show that root hairs are the main determinant for the low mycorrhiza dependency of barley. The poor ability of root hairless barley to acquire $\mathrm{P}$ can be fully counteracted by mycorrhizas and the P uptake by four out of seven fungi even exceeded the uptake by uncolonized roots with root hairs. Therefore, the root-external mycelium of AM fungi constitutes an alternative and effective pathway for root $\mathrm{P}$ uptake. The additional fungus-mediated $\mathrm{P}$ uptake was in most cases not translated into comparable increases in dry weights, which were often lower in mycorrhizal hairless plants than in non-mycorrhizal or wild-type plants with similar shoot P concentration. Such relationship between mycorrhizal and non-mycorrhizal plants is commonly observed (see, e.g. Stribley, Tinker \& Rayner 1980; Koide, Goff \& Dickie 2000) and we conclude that P taken up by root hairs is generally used more effectively in plant growth than $\mathrm{P}$ provided via AM fungi. However, the situation is diverse as translation of $\mathrm{P}$ into increased plant growth was very effective with one of the AM fungi included in our 
study. It may therefore be rewarding to screen AM fungi for ability to convert acquired $\mathrm{P}$ into additional plant growth.

\section{ACKNOWLEDGMENTS}

Seeds for experiments 1 and 2 were propagated and kindly supplied by Dr T.S. Gahoonia, The Royal Veterinary and Agricultural University, Frederiksberg, Denmark. Thanks to Anette Olsen for skilful technical assistance.

\section{REFERENCES}

Baldwin J.P., Tinker P.B. \& Nye P.H. (1972) Uptake of solutes by multiple root systems from soil. 2. Theoretical effects of rooting density and pattern on uptake of nutrients from soil. Plant and Soil 36, 693-?.

Baon J.B., Smith S.E. \& Alston A.M. (1994) Growth response and phosphorus uptake of rye with long and short root hairs: Interactions with mycorrhizal infection. Plant and Soil 167, 247-254.

Barber S.A. (1984) Soil Nutrient Bioavailability - a Mechanistic Approach. Wiley-Interscience, New York, USA.

Bates T.R. \& Lynch J.P. (2000a) Plant growth and phosphorus accumulation of wild type and two root hair mutants of Arabidopsis thaliana (Brassicaceae). American Journal of Botany 87, 958-963.

Bates T.R. \& Lynch J.P. (2000b) The efficiency of Arabidopsis thaliana (Brassicaceae) root hairs in phosphorus acquisition. American Journal of Botany 87, 964-970.

Baylis G.T.S. (1970) Root hairs and phycomycetous mycorrhizas in phosphorus-deficient soil. Plant and Soil 33, 713-716.

Berta G., Fusconi A. \& Trotta A. (1993) VA Mycorrhizal infection and the morphology and function of root systems. Environmental and Experimental Botany 33, 159-173.

Bolan N.S., Robson A.D. \& Barrow N.J. (1984) Increasing phosphorus supply can increase the infection of plant roots by vesicular arbuscular mycorrhizal fungi. Soil Biology and Biochemistry 16, 419-420.

Burleigh S.H., Cavagnaro T. \& Jakobsen I. (2002) Functional diversity of arbuscular mycorrhizas extends to the expression of plant genes involved in $\mathrm{P}$ nutrition. Journal of Experimental Botany 53, 1593-1601.

Cavagnaro T.R., Smith F.A., Smith S.E. \& Jakobsen I. (2005) Functional diversity in arbuscular mycorrhizas: exploitation of soil patches with different phosphate enrichment differs among fungal species. Plant, Cell and Environment doi: 10.1111/j.13653040.2005.01310.x

Clarke C. \& Mosse B. (1981) Plant-growth responses to vesiculararbuscular mycorrhiza. 12. Field inoculation responses of barley at 2 soil-P levels. New Phytologist 87, 695-703.

Föhse D. \& Jungk A. (1983) Influence of phosphate and nitrogen supply on root hair formation of rape, spinach and tomato plants. Plant and Soil 74, 359-368.

Föhse D., Claassen N. \& Jungk A. (1991) Phosphorus efficiency of plants.2. Significance of root radius, root hairs and cation-anion balance for phosphorus influx in 7 plant species. Plant and Soil 132, 261-272.

Fusconi A., Tagliasacchi A.M., Berta G., Trotta A., Brazzaventre S., Ruberti F. \& Scannerini S. (2000) Root apical meristems of Allium porrum L. as affected by arbuscular mycorrhizae and phosphorus. Protoplasma 214, 219-226.

Gahoonia T.S. \& Nielsen N.E. (2003) Phosphorus (P) uptake and growth of a root hairless barley mutant (bald root barley, brb) and wild type in low- and high-P soils. Plant, Cell and Environment 26, 1759-1766.

Gahoonia T.S., Care D. \& Nielsen N.E. (1997) Root hairs and phosphorus acquisition of wheat and barley cultivars. Plant and Soil 191, 181-188.

Gahoonia T.S., Nielsen N.E., Joshi P.A. \& Jahoor A.A. (2001) root hairless barley mutant for elucidating genetic of root hairs and phosphorus uptake. Plant and Soil 235, 211-219.

Graham J.H., Leonard R.T. \& Menge J.A. (1981) Membranemediated decrease in root exudation responsible for phosphorus inhibition of vesicular-arbuscular mycorrhiza formation. Plant Physiology 68, 548-552.

Harrison M.J., Dewbre G.R. \& Liu J. (2002) A phosphate transporter from Medicago truncatula involved in the acquisition of phosphate released by arbuscular mycorrhizal fungi. Plant Cell 14, 1-17.

Jakobsen I. (1983) Vesicular arbuscular mycorrhiza in field-grown crops. II. Effect of inoculation on growth and nutrient uptake in barley at two phosphorus levels in fumigated soil. New Phytologist 94, 595-604.

Jakobsen I. \& Nielsen E.N. (1983) Vesicular arbuscular mycorrhiza in field grown crops. I. Mycorrhizal infection in cereals and peas at various times and soil depths. New Phytologist 93, 401-413.

Jakobsen I. \& Rosendahl L. (1990) Carbon flow into soil and external hyphae from roots of mycorrhizal cucumber plants. New Phytologist 115, 77-83.

Jakobsen I., Abbott L.K. \& Robson A.D. (1992a) External hyphae of vesicular-arbuscular mycorrhizal fungi associated with Trifolium subterraneum L. 2. Hyphal transport of 32P over defined distances. New Phytologst 120, 509-516.

Jakobsen I., Abbott L.K. \& Robson A.D. (1992b) External hyphae of vesicular-arbuscular mycorrhizal fungi associated with Trifolium subterraneum. 1: Spread of hyphae and phosphorus inflow into roots. New Phytologist 120, 371-380.

Jakobsen I., Smith S.E. \& Smith F.A. (2002) Function and diversity of arbuscular mycorrhizae in carbon and mineral nutrition. In Mycorrhizal Ecology (eds M.G.A. vanderHeijden \& I.R. Sanders), pp. 75-92. Springer, Berlin, Germany.

Jansa J., Mozafar A. \& Frossard E. (2003) Long-distance transport of $\mathrm{P}$ and $\mathrm{Zn}$ through the hyphae of an arbuscular mycorrhizal fungus in symbiosis with maize. Agronomie 23, 481-488.

Jensen A. (1984) Responses of barley, pea and maize to inoculation with different vesicular-arbuscular mycorrhizal fungi in irradiated soil. Plant and Soil 78, 315-323.

Jensen A. \& Jakobsen I. (1980) The occurrence of vesicular-arbuscular mycorrhiza in barley and wheat grown in some Danish soils with different fertilizer treatments. Plant and Soil 55, 403 413.

Joner E.J., Magid J., Gahoonia T.S. \& Jakobsen I. (1995) P depletion and activity of phosphatases in the rhizosphere of mycorrhizal and non-mycorrhizal cucumber (Cucumis sativus L). Soil Biology and Biochemistry 27, 1145-1151.

Karandashov V., Nagy R., Wegmuller S., Amrhein N. \& Bucher M. (2004) Evolutionary conservation of a phosphate transporter in the arbuscular mycorrhizal symbiosis. Proceedings of the National Academy of Sciences of the USA 101, 6285-6290.

Khaliq A. \& Sanders F.E. (2000) Effects of vesicular-arbuscular mycorrhizal inoculation on the yield and phosphorus uptake of field-grown barley. Soil Biology and Biochemistry 32, 16911696.

Koide R.T., Goff M.D. \& Dickie I.A. (2000) Component growth efficiencies of mycorrhizal and non-mycorrhizal plants. New Phytologist 148, 163-168.

Li X.-L., George E. \& Marschner H. (1991) Extension of the phosphorus depletion zone in VA-mycorrhizal white clover in a calcareous soil. Plant and Soil 136, 41-48. 
Liu H., Trieu A.T., Blaylock L.A. \& Harrison M.J. (1998) Cloning and characterization of two phosphate transporters from Medicago truncatula roots. Regulation in response to phosphate and to colonization by arbuscular mycorrhizal (AM) fungi. Molecular Plant - Microbe Interactions 11, 14-22.

Ma Z., Bielenberg D.G., Brown K.M. \& Lynch J.P. (2001a) Regulation of root hair density by phosphorus availability in Arabidopsis thaliana. Plant, Cell and Environment 24, 459-467.

Ma Z., Walk T.C., Marcus A. \& Lynch J.P. (2001b) Morphological synergism in root hair length, density, initiation and geometry for phosphorus acquisition in Arabidopsis thaliana: a modeling approach. Plant and Soil 236, 221-235.

Motulsky H.J. (1999) Analyzing Data with Graphpad Prism. GraphPad Software Inc, San Diego CA, USA.

Murphy J. \& Riley J.P. (1962) A modified single solution method for the determination of phosphate in natural water. Analytica Chimica Acta 27, 31-36.

Newman E.I. (1966) A method for estimating the total length of root in a sample. Journal of Applied Ecology 3, 139-145.

Nye P.H. \& Tinker P.B. (1977) Solute Movement in the Soil-Root System. Blackwell, Oxford, UK.

Olsen S.R., Cole C.V., Watanabe F.S. \& Dean L.A. (1954) Estimation of Available Phosphorus in Soils by Extraction with Sodium Bicarbonate, Circular No. 939. USDA, Washington, DC, USA.

Paszkowski U. \& Boller T. (2002) The growth defect of Irt1, a maize mutant lacking lateral roots, can be complemented by symbiotic fungi or high phosphate nutrition. Planta 214, 584-590.

Paszkowski U., Kroken S., Roux C. \& Briggs S. (2002) Rice phosphate transporters include an evolutionary divergent gene specifically activated in arbuscular mycorrhizal symbiosis. Proceedings of the National Academy of Sciences of the USA 99, 13324-13329.

Payne R.W. (ed.) (2002) The Guide to Genstat Release 6.1- Part 1: Syntax and DATA Management, GenStat Committee. VSN International, Hemel Hempstead, UK.

Phillips J.M. \& Hayman D.S. (1970) Improved procedures for clearing roots and staining parasitic and vesicular-arbuscular mycorrhizal fungi for rapid assessment of infection. Transactions of British Mycological Society 55, 158-160.

Rausch C., Daram P., Brunner S., Jansa J., Laloi M., Leggewie G., Amrhein N. \& Bucher M. (2001) A phosphate transporter expressed in arbuscule-containing cells in potato. Nature 414, $462-466$.

Sanders F.E. (1975) The effect of foliar-applied phosphate on the mycorrhizal infections of onion roots. In Endomycorrhizas (eds F.E. Sanders, B. Mosse \& P.B. Tinker), pp. 261-276. Academic Press, London, UK.
Schiefelbein J.W. \& Somerville C. (1990) Genetic control of root hair development in Arabidopsis thaliana. Plant Cell 2, 235-243. Schneider K., Mathur J., Boudonck K., Wells B., Dolan L. \& Roberts K. (1998) The root hairless 1 gene encodes a nuclear protein required for root hair initiation in Arabidopsis. Genes and Development 12, 2013-2021.

Schweiger P.F., Robson A.D. \& Barrow N.J. (1995) Root hair length determines beneficial effect of a Glomus species on shoot growth of some pasture species. New Phytologist 131, 247-254.

Silberbush M. \& Barber S.A. (1983) Sensitivity of simulated phosphorus uptake to parameters used by a mechanistic-mathematical model. Plant and Soil 74, 93-100.

Smith F.A., Jakobsen I. \& Smith S.E. (2000) Spatial differences in acquisition of soil phosphate between two arbuscular mycorrhizal fungi in symbiosis with Medicago truncatula. New Phytologist 147, 357-366.

Smith S.E., Smith F.A. \& Jakobsen I. (2003) Mycorrhizal fungi can dominate phosphate supply to plants irrespective of growth responses. Plant Physiology 133, 16-20.

Stribley D.P. \& Snellgrove R.C. (1984) Physiological changes accompanying mycorrhizal infection in leek. In Proceedings of the 6th North American Conference on Mycorrhizae (ed. R. Molina), p. 395. Forest Research Laboratory, Corvallis, OR, USA.

Stribley D.P., Tinker P.B. \& Rayner J.H. (1980) Relation of internal phosphorus concentration and plant weight in plants infected by vesicular-arbuscular mycorrhizas. New Phytologist 86, 261-266.

Suzuki N., Taketa S. \& Ichii M. (2003) Morphological and physiological characteristics of a root-hairless mutant in rice (Oryza sativa L.). Plant and Soil 255, 9-17.

Thomson B.D., Robson A.D. \& Abbott L.K. (1991) Soil mediated effects of phosphorus on the formation mycorrhizas Scutellispora calospora (Nicol and Gerd) Walker and Sanders on subterranean clover. New Phytologist 118, 463-469.

Wen T.J. \& Schnable P.S. (1994) Analyses of mutants of 3 genes that influence root hair development in Zea mays (Gramineae) suggest that root hairs are dispensable. American Journal of Botany 81, 833-842.

Zhu Y.G., Smith F.A. \& Smith S.E. (2003) Phosphorus efficiencies and responses of barley (Hordeum vulgare L.) to arbuscular mycorrhizal fungi grown in highly calcareous soil. Mycorrhiza 13, 93-100.

Received 3 December 2004; received in revised form 21 January 2005; accepted for publication 11 February 2005 